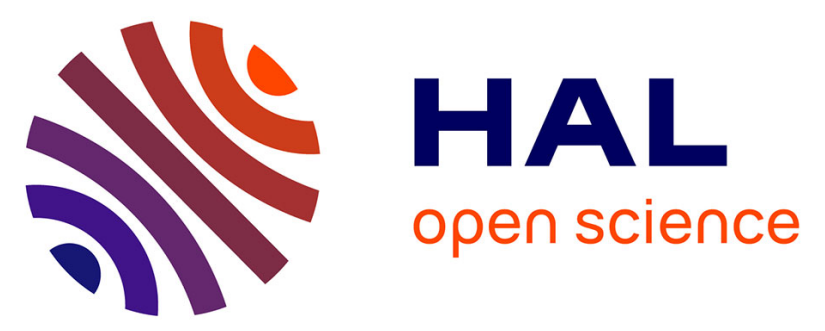

\title{
Cross-Linking between Sodalite Nanoparticles and Graphene Oxide in Composite Membranes to Trigger High Gas Permeance, Selectivity, and Stability in Hydrogen Separation
}

Hailing Guo, Guodong Kong, Ge Yang, Jia Pang, Zixi Kang, Shou Feng, Lei Zhao, Lili Fan, Liangkui Zhu, Aurelie Vicente, et al.

\section{To cite this version:}

Hailing Guo, Guodong Kong, Ge Yang, Jia Pang, Zixi Kang, et al.. Cross-Linking between Sodalite Nanoparticles and Graphene Oxide in Composite Membranes to Trigger High Gas Permeance, Selectivity, and Stability in Hydrogen Separation. Angewandte Chemie, 2020, 132 (15), pp.6343-6347. 10.1002/ange.201915797 . hal-02893843

\section{HAL Id: hal-02893843 https://hal.science/hal-02893843}

Submitted on 27 Nov 2020

HAL is a multi-disciplinary open access archive for the deposit and dissemination of scientific research documents, whether they are published or not. The documents may come from teaching and research institutions in France or abroad, or from public or private research centers.
L'archive ouverte pluridisciplinaire HAL, est destinée au dépôt et à la diffusion de documents scientifiques de niveau recherche, publiés ou non, émanant des établissements d'enseignement et de recherche français ou étrangers, des laboratoires publics ou privés. 


\section{Cross-linking between sodalite nanoparticles and graphene oxide in composite membranes triggers high gas permeance, selectivity and stability in hydrogen separation}

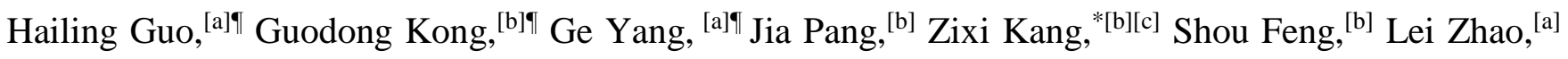
Lili Fan, ${ }^{[b][c]}$ Liangkui Zhu, ${ }^{[\mathrm{d}]}$ Aurélie Vicente, ${ }^{[\mathrm{e}]}$ Peng Peng, ${ }^{[\mathrm{a}][\mathrm{e}]}$ Zifeng Yan, ${ }^{[\mathrm{a}]}$ Daofeng Sun, ${ }^{*[\mathrm{~b}][\mathrm{c}]}$ Svetlana Mintova, ${ }^{[}[\mathrm{a}][\mathrm{e}]$

a, e Dr. Hailing Guo, Prof. Svetlana Mintova, Prof. Zifeng Yan, Ge Yang, Lei Zhao, Peng Peng, Dr. Aurélie Vicente a: State Key Laboratory of Heavy Oil Processing, Key Laboratory of Catalysis, China University of Petroleum (East China), 266555 Qingdao, China. e: Laboratoire Catalyse et Spectrochimie (LCS), Normandie University, ENSICAEN, CNRS, 6 boulevard du Marechal Juin, 14050 Caen, France. E-mail: mintova@ensicaen.frb,

b, c Dr. Zixi Kang, Prof. Daofeng Sun, Jia Pang, Shou Feng, Guodong Kong, Dr. Lili Fan, b: College of Science, c: School of Materials Science and Engineering, China University of Petroleum (East China), 266580 Qingdao, China. Email: dfsun@upc.edu.cn, kzx@upc.edu.cn

d Liangkui Zhu: State Key Laboratory of Inorganic Synthesis \& Preparative Chemistry, Jilin University, 130023 Changchun, China

II H. Guo, G. Kong and G. Yang contributed equally to this work.

Keywords: SOD nanocrystals $\bullet$ graphene oxide matrix $\bullet$ membrane separation $\bullet$ synergistic effect $\bullet$ hydrogen separation 
Abstract: Thin membranes (900 nm) were prepared by direct transformation of infiltrated amorphous precursor nanoparticles, impregnated in a graphene oxide (GO) matrix, into hydroxy sodalite (SOD) nanocrystals under environmentally friendly and green conditions (organic template-free, hydrothermal treatment at $60{ }^{\circ} \mathrm{C}$ for $\left.40 \mathrm{~h}\right)$. The amorphous precursor particles rich in silanols $(\mathrm{Si}-\mathrm{OH})$ enhanced the interactions with the GO, thus leading to the formation of highly adhesive and stable SOD/GO membranes via strong bonding, as revealed by FTIR, ${ }^{29} \mathrm{Si}$ NMR and XPS. The cross-linking of SOD nanoparticles with the GO in the membranes promoted both the high gas permeance and enhanced selectivity towards hydrogen from a mixture containing $\mathrm{CO}_{2}$ and water in contrast to the pure $\mathrm{GO}$ with larger gas permeance but a severe decline in selectivity due to the swelled layer spacing by water. The moisture resistance and steady separation performance of the SOD/GO membranes in the $\mathrm{H}_{2} / \mathrm{CO}_{2}$ separation at high temperature $\left(200{ }^{\circ} \mathrm{C}\right)$ under water vapor $(4 \mathrm{~mol} . \%)$ was attained. The SOD/GO membrane exhibits $\mathrm{H}_{2}$ permeance of $\sim 4900 \mathrm{GPU}$ and $\mathrm{H}_{2} / \mathrm{CO}_{2}$ selectivity of 56 , with no degradation in performance during the test of $50 \mathrm{~h}$. 
Small pore zeolites with uniform pores and stable frameworks are ideal candidates to build molecular sieving membrane. ${ }^{1}$ Framework structures such as zeolites with pores constructed of 8 -membered rings (8MR) or larger (10MR), such as LTA, CHA and MFI, etc. have been widely studied as components of membranes for both gas and liquid separations. ${ }^{2}$ Recently, hydroxy sodalite (SOD) with 6MR and small aperture size of $2.9 \AA$ received attention due to the molecular sieving effect allowing separation of hydrogen from other components with similar sizes. ${ }^{3}$ The results reported up to now proved that SOD nanocrystals are efficient in sieving $\mathrm{H}_{2}$ from gas mixtures.

Membranes that can selectively separate $\mathrm{CO}_{2}$ from $\mathrm{H}_{2}$ are of significant interest for applications in the water-gas shift reaction. ${ }^{4}$ Coal-derived syngas which typically contains $56 \% \mathrm{H}_{2}$ and $40 \% \mathrm{CO}_{2}(50$ bar at $100-300{ }^{\circ} \mathrm{C}$ ) is subjected to $\mathrm{CO}_{2}$ removal and can be subsequently used, for example, in hydrogen-fuel turbines. The concentrated $\mathrm{CO}_{2}$ can be sequestered underground or employed further in enhanced oil recovery processes. ${ }^{4}$ Compared to pressure swing adsorption (PSA) and fractional/cryogenic distillation, membrane separation is considered a promising process due to its low energy requirements, ability for continuous operation, low investment cost, easy operation, and cost effectiveness. ${ }^{5}$ The membranes for $\mathrm{H}_{2} / \mathrm{CO}_{2}$ separation from coal-derived syngas are expected to have a high $\mathrm{H}_{2} / \mathrm{CO}_{2}$ selectivity at elevated temperature in the presence of water vapor. This is of critical importance for the pre-combustion capture of $\mathrm{CO}_{2}$ after the water gas shift reaction where water is always present. ${ }^{4}$

The SOD based membranes currently available for $\mathrm{H}_{2}$ separation are scarce due to the following reasons: (1) the preparation of large area SOD polycrystalline membranes is challenging due to the formation of inevitable intercrystallite defects weakening their molecule sieving effect; ${ }^{6}(2)$ the classical micronsized zeolite crystals including SOD with long diffusion paths result in slow sorption kinetics and unavoidable micropore blockage $;^{7}(3)$ the process of preparation of mixed matrix membranes (MMMs) containing zeolites and polymer matrix is considerably simplified, ${ }^{8}$ while the weak interactions of inorganic-organic materials and the relative low free volume of membrane may limit their selectivity and permeance. ${ }^{9}$ 
Graphene oxide (GO), a two-dimensional (2D) material, has been prepared as ultra-thin laminar membranes for gas and liquid separation. ${ }^{10}$ In order to ensure uniform pore distribution and even interlayer spacing in the GO membrane, three-dimensional nanoporous crystals were introduced into the GO laminates. ${ }^{11}$ A stable metal-organic framework (MOF) material (UiO-66) with a pore size of $6 \AA$ has been added into reduced graphene oxide (rGO) membrane; the composite membrane showed enhanced performance in removal of dye molecules from water. ${ }^{11 \mathrm{c}}$ Yao etc. have intercalated amino-functionalized UiO-66 (UiO-66- $\mathrm{NH}_{2}$ ) into GO layers; the final composite membrane (UiO-66- $\left.\mathrm{NH}_{2} / \mathrm{GO}\right)$ demonstrated $\mathrm{H}_{2} / \mathrm{CO}_{2}$ selectivity of $6.39 .{ }^{12}$ As shown, ${ }^{11-12}$ the size and shape of nanoparticles (filters) and their dispersion in the GO (matrix) have a far-reaching impact on improving separation property, similar to the case of polymers based mixed matrix membrane. ${ }^{13}$

In this paper we report the preparation of membranes by direct transformation of amorphous precursor nanoparticles infiltrated in graphene oxide (GO) into hydroxy sodalite (SOD) nanocrystals at $60{ }^{\circ} \mathrm{C}$ for 40 hours. Where, the highly selective nanosized SOD particles are the filler and the GO is the matrix; the composite SOD-GO membrane can be considered as a mixed matrix membrane (MMM). Precisely control of the size and distribution of the SOD nanocrystals (filter) in the GO matrix strengthen the crosslinking between them and maintain the multi-channel synergy caused by the flexible 2D layered GO and the rigid cages of SOD nanocrystals. A schematic representation of the preparation of this membrane is shown in Scheme S1.

The isolated precursor nanoparticles were X-ray amorphous and no Bragg peaks in the pattern were observed. While the Fourier transform infrared spectrum (FTIR) of the amorphous precursor particles (Fig. S1) contains a broad band at $\sim 990 \mathrm{~cm}^{-1}$ assigned to the T-O-T asymmetric stretch, and bands at 715 and $663 \mathrm{~cm}^{-1}$ due to the T-O-T symmetric stretch. ${ }^{14}$ Another broad band at $860 \mathrm{~cm}^{-1}$ is assigned to silanol (Si-OH) bending mode related to the silicon atoms linked to one hydroxyl group. ${ }^{15}$ The broad peak centered at about $1645 \mathrm{~cm}^{-1}$ is assigned to the $\mathrm{O}-\mathrm{H}$ stretching vibration. This information confirms that a large number of disordered and isolated units (sodalite cage) are present in the amorphous particles prior 
transformation into SOD nanocrystals with long-range ordering. The high concentration of Si-OH in the amorphous precursor particles benefit the interactions with the parent GO with abundant oxygencontaining groups thus improving the direct confinement transformation of the amorphous into crystalline SOD nanoparticles. The size of precursor particles infiltrated in the GO is about $12 \mathrm{~nm}$ (Fig. S2).

The GO lamellar structure was stable under the infiltration of the precursor amorphous nanoparticles due to the atomic-size thickness and larger lateral size of the GO (Fig. S3). Two samples Pre/GO-M1 and Pre/GO-M2 were prepared (Tab. S1), whose structure are shown in Fig. S4 in comparison to the pure GO membrane. The thickness of Pre/GO-M1 and Pre/GO-M2 samples increase to 7 8 $\mu \mathrm{m}$ and 12 13 $\mu \mathrm{m}$ respectively, in comparison to the pure GO membrane with a thickness of 400 500 nm. The transformation of the Pre/GO-M1 and Pre/GO-M2 into membranes was carried out under treatment with 23 wt. $\% \mathrm{NaOH}$ solution at $60{ }^{\circ} \mathrm{C}$ for $40 \mathrm{~h}$. The resulted membranes are abbreviated as SOD/GO-M1 and SOD/GO-M2. For clarity, the characterization and performance of SOD/GO-M1 membrane are presented in the manuscript, while all data of SOD/GO-M2 are summarized in the SI. The XRD patterns of the powder peeled off SOD/GO-M1 membrane after treatment for different periods (5, 20 and $40 \mathrm{~h}$ ) are shown in Fig. S5a. The average crystal size of the SOD crystals isolated from the SOD/GO-M1 membrane is about $12 \mathrm{~nm}$ according for the Scherrer's equation. Moreover, the intensity of the [110] peak belonging to SOD phase gradually increases with the prolongation of reaction time indicating the transformation of amorphous nanoparticles in GO matrix. The XRD pattern of the SOD/GO-M1 thin membrane contains the main peaks corresponding to the nylon substrate, due to the smaller particle size and higher dispersion of SOD in GO matrix (Fig. S5b). Additionally, continuous, smooth and compact SOD/GO-M1 membrane was obtained and no extra-particles were found on its surface in comparison with the precursor (Pre/GOM1) membrane (Fig. 1 and Fig. S6, S7). The cross-section SEM images reveal the thickness decreases from $7 \sim 8 \mu \mathrm{m}$ (Pre/GO-M1, Fig. 1d) to $0.9 \mu \mathrm{m}$ (SOD/GO-M1, Fig. 1e) after the transformation of amorphous precursor particles into crystalline SOD. By infiltrating more amorphous nanoparticles (Table $\mathrm{S} 1$ ), the final thickness of the membrane increased to $1.1 \sim 1.2 \mu \mathrm{m}$ (Fig. 1f). The sodium hydroxide added 
to the Pre/GO membrane removed the excess of surface amorphous particles, and also promoted the transformation of the GO interlayered particles into SOD crystals during the treatment. The Energy dispersive spectroscopy (EDS) mapping results (Fig. S7) confirmed the uniform distribution of SOD nanocrystals in the composite membranes. The smooth surface of the membrane is proven by AFM (Fig. S8 and Table S2); these results are consistent with the SEM observations (Fig. 1). The surface of the SOD/GO-1 and SOD/GO-2 membranes becomes smoother in comparison to the surface of Pre/GO membrane. Furthermore, the SOD/GO-M1 membrane inherits the highest mechanical properties (248 Gpa elastic modulus and 0.6 Gpa hardness) among all membranes (Fig. S9).

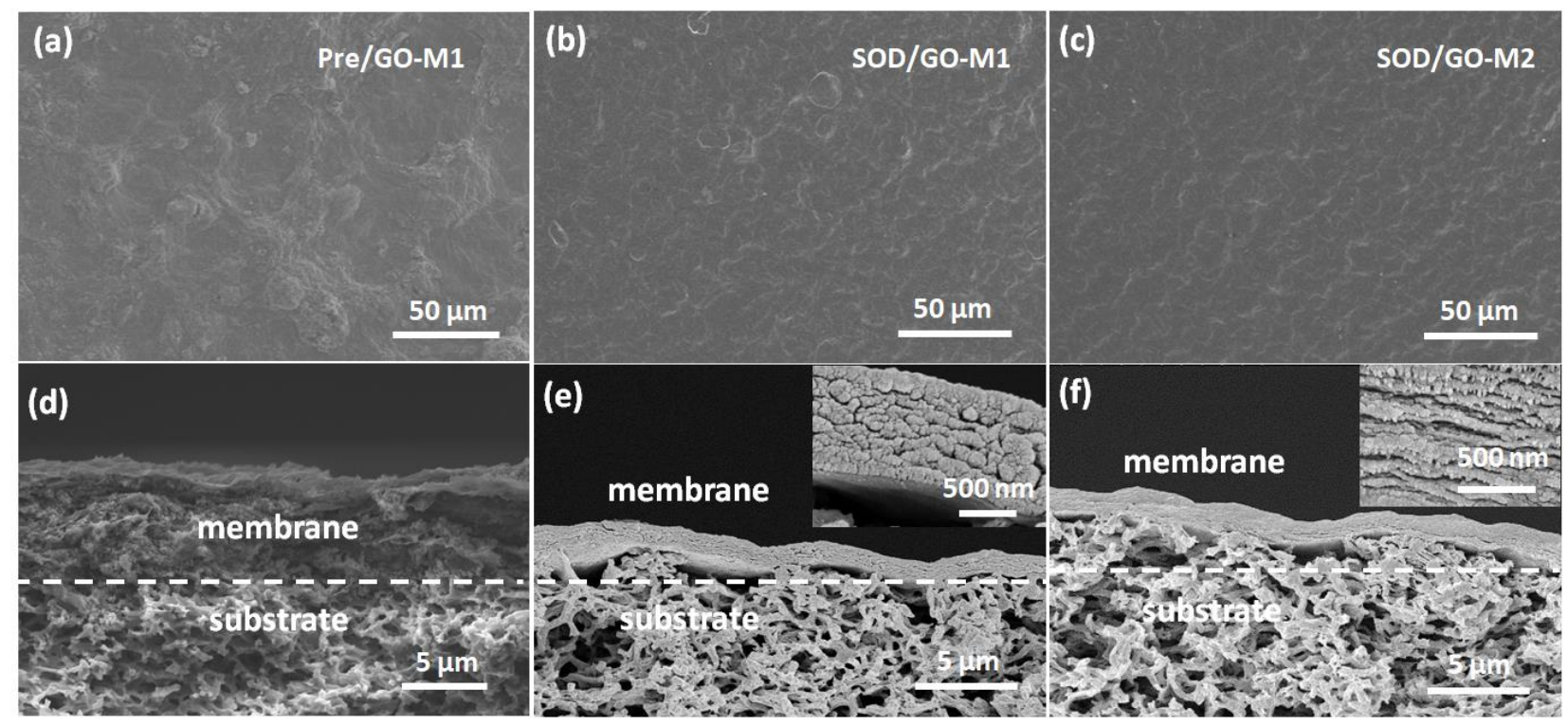

Figure 1. (a, b, c) Top-view SEM images Pre/GO-M1, SOD/GO-M1 and SOD/GO-M2 membranes, respectively; (d, e, f) cross-section images of Pre/GO-M1, SOD/GO-M1 and SOD/GO-M2 membranes, respectively.

The direct transformation of amorphous precursor particles into SOD nanocrystals in the GO avoids the formation of non-selective space between the GO and the SOD due to direct interactions via strong bonding. The broad $\mathrm{O}-\mathrm{H}$ stretching vibration band shifts from $1641 \mathrm{~cm}^{-1}$ (Pre/GO-M1) to $1600 \mathrm{~cm}^{-1}$ (SOD/GO-M1) as shown in the FTIR spectra confirming the strong hydrogen bonding (Fig. 2a). ${ }^{16}$ The Si-OH peak $\left(862 \mathrm{~cm}^{-1}\right)$ was weakened, while the intensity of the T-O-T peak $\left(663 \mathrm{~cm}^{-1}\right)$ increased, 
indicating the transformation of amorphous precursor particles into SOD crystals. The low content Si-O$\mathrm{C}$ bond peak $\left(1053 \mathrm{~cm}^{-1}\right)^{17}$ is submerged by wide $\mathrm{Si}-\mathrm{O}-\mathrm{Si}$ bond peak $\left(998 \mathrm{~cm}^{-1}\right)$. Further the interactions of the GO with the amorphous precursor and crystalline SOD nanoparticles is studied by ${ }^{29} \mathrm{Si}$ NMR (Fig. 2b). The ${ }^{29} \mathrm{Si}$ DP NMR spectrum of Pre/GO-M1 presents a broad signal at $-86.5 \mathrm{ppm}$ which is typical for amorphous silicon. While a sharp peak at $-86.5 \mathrm{ppm}$ appeared in the spectrum of SOD/GO-M1 and pure SOD which is related with the formation of $\mathrm{Q} 4, \mathrm{Si}$ (4Al) species; the Q4 species are a part of the secondary building units of the sodalite crystals (SOD cages). A shoulder at $-83.0 \mathrm{ppm}$ corresponds to Q3, Si (3Al, $1 \mathrm{OH})$, is in a good agreement with the chemical composition of the samples ( $\mathrm{Si} / \mathrm{Al} \neq 1)$. More interestingly, the DP-NMR spectrum of SOD/GO-M1 doesn't contain any peaks in the T region ${ }^{18}$ (-60 to $-70 \mathrm{ppm}$ ), which confirms that no Si-C links are formed in both samples. The sharp signal at $-86.5 \mathrm{ppm}$ in the ${ }^{29} \mathrm{Si}$ CP NMR spectrum of the SOD/GO-M1 in comparison to the Pre/GO-M1 is due to absence of silanol groups ( $\mathrm{Si}-\mathrm{OH})$ and close proximity between zeolite nanocrystals and the GO matrix. While this signal is not so intense in the pure SOD powder sample (Fig. S10). The ${ }^{29} \mathrm{Si}$ DP NMR spectrum of SOD contains a peak at $-86.5 \mathrm{ppm}$ corresponding to $\mathrm{Si}-\mathrm{O}-\mathrm{Al}(66 \%)$ and a peak at $-83.5 \mathrm{ppm}$ corresponding to $\mathrm{SiOH}$ (34\%) (Fig. S11). While the spectrum of SOD/GO-M1 contains a peak -86.5 ppm corresponding to Si-O$\mathrm{Al}$ and $\mathrm{Si}-\mathrm{O}-\mathrm{C}(81 \%)$ and a peak at $-83.0 \mathrm{ppm}$ corresponding to $\mathrm{SiOH}(19 \%)$. The formation of Si-O-C bond is demonstrated by a decrease of the peak at $-83.0 \mathrm{ppm}$ in the SOD/GO-M1 in comparison to the SOD and the increase of the peak at $-86.5 \mathrm{ppm}$ corresponding to the presence of Si-O-Al. Based on the XPS carbon (C 1s) spectra of samples Pre/GO-M1 and SOD/GO-M1 (Fig. 2c and Fig. S12), we found that the content of $\mathrm{C}$ in oxidation state increase and the binding energy for $\mathrm{C}-\mathrm{O}, \mathrm{C}=\mathrm{O}$ and $\mathrm{O}-\mathrm{C}=\mathrm{O}$ shifted to the higher value for sample SOD/GO-M1 thus indicating the stronger binding force between the hydroxyl groups of SOD and GO. Moreover, the high-resolution XPS oxygen (O 1s) spectrum of sample Pre/GO-M1 with a binding energy of $533.9 \mathrm{eV}$ represents $\mathrm{C}-\mathrm{O}-\mathrm{C}$ (1.5 at. \%). While the deconvoluted O 1s peaks of sample SOD/GO-M1 show a shift to $535.90 \mathrm{eV}$ (6.49 at. \%), thus, confirming the formation of Si-O-C bond and the crosslinking between the GO and SOD nanocrystals. The high adhesion and 
strong bonding between GO and SOD ensure great selectivity and long-time stability of the SOD/GO-1 membrane for separation of hydrogen from a mixture containing $\mathrm{CO}_{2}$ and water.

The single gas permeation on different membranes (pristine GO, SOD/GO-M1 and SOD/GO-M2) were tested by the soap film flowmeter at the pressure of 1.2 bar (Table S3 and Fig. S13). ${ }^{19}$ The pristine GO membrane shows poor ideal selectivity for all gas pairs, due to the more surface defects and large layer spacing. The low ideal selectivity of 6.0 for $\mathrm{H}_{2} / \mathrm{CO}_{2}$ is obtained owing to the delayed diffusion of trapped $\mathrm{CO}_{2}$ by carboxylic acid groups in the GO in the channel. ${ }^{20}$ The SOD/GO-M1 membrane possesses a significantly improved $\mathrm{H}_{2} / \mathrm{CO}_{2}$ separation performance $\left(\mathrm{H}_{2} / \mathrm{CO}_{2}\right.$ selectivity of 85.0$)$ in comparison with the pristine GO membranes. The uniform cages of SOD (size of $0.29 \mathrm{~nm}$ ) in the SOD/GO-M1 membrane can efficiently sieve $\mathrm{H}_{2}(0.28 \mathrm{~nm})$ from $\mathrm{CO}_{2}(0.33 \mathrm{~nm})$. However, the SOD/GO-M2 with excessive amount of SOD (inhomogeneous texture structure, more voids, and weak crosslinking between GO and SOD as proved by Fig. S14), shows much lower ideal selectivity (11.0) for $\mathrm{H}_{2} / \mathrm{CO}_{2}$. The activation energy of permeation $\left(E_{a c t}\right)$ based on the gas permeance at different temperature is calculated. As shown in Fig. S15 and Table S4, the SOD/GO-M1 exhibits higher $\mathrm{E}_{\text {act }}$ for $\mathrm{CO}_{2}\left(21.21 \mathrm{~kJ} \mathrm{~mol}^{-1}\right)$ than that of $\mathrm{H}_{2}(12.43$ $\mathrm{kJ} \mathrm{mol}^{-1}$ ), caused by the combined action of SOD and GO (Scheme S2). The $\mathrm{E}_{\text {act }}$ is related to the diffusion activation energy $(E D)$ and heat of adsorption $E_{\text {ast }}\left(E_{a c t}=E D+E_{a s t}\right) .{ }^{21}$ Due to the stronger adsorption of $\mathrm{CO}_{2}$ on $\mathrm{GO}$, the $\mathrm{E}_{\text {ast }}$ for $\mathrm{CO}_{2}$ on the composite membrane is expected to be higher than that of $\mathrm{H}_{2}$. Thus, the diffusion activation energy of $\mathrm{CO}_{2}$ through the composite membrane is much higher than that of $\mathrm{H}_{2}$ as $\mathrm{CO}_{2}$ takes a more complex pathway through the membrane (Scheme S2). The increasing trend of hydrogen permeability with the increase of temperature also confirms that gas transport in the membrane is mainly dominated by micropore diffusion. ${ }^{22}$ Combining GO with SOD promotes the multiple channels for gas transmission (Scheme S2), and the close cross-linking of GO and SOD improves the gas separation efficiency. The separation is dominated by the molecular sieving effect of the SOD crystals (66 w.t.\% Fig. S16), and other side factors also play a role such as high hydrogen selectivity GO owing to the strong affinity between $\mathrm{CO}_{2}$ and $\mathrm{GO}$. A negligible amount of amorphous silica is possibly present in the sample 
that can contribute to the hydrogen selectivity too but is difficult to be quantified using TEM (Fig. S17). ${ }^{23}$ The GO interlayer spacing helps water molecules to penetrate within the membranes; the tight crosslinking between GO and SOD is necessary to achieve high efficiency separation due to the mitigation of interface voids.

(a)

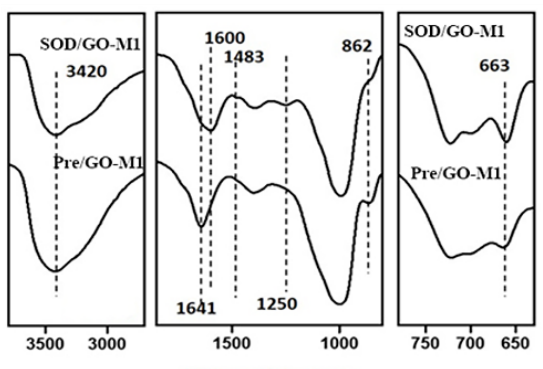

(b)

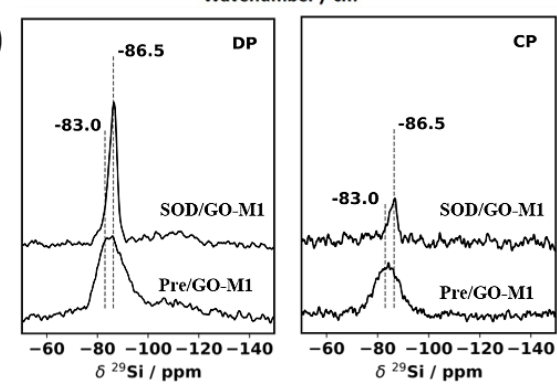

(c)

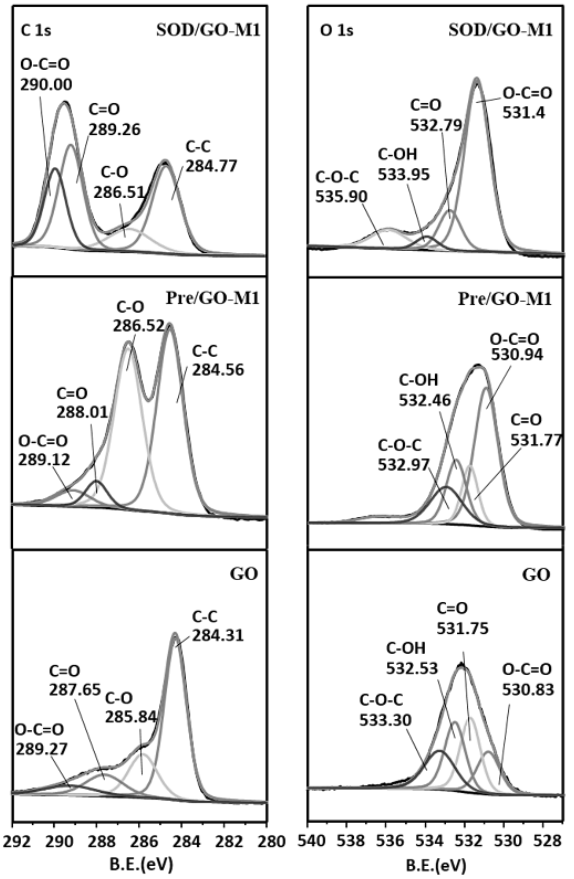

Figure 2. (a) FTIR, (b) ${ }^{29} \mathrm{Si}$ solid NMR (Direct Pulse NMR (DP)-left and Cross-Polarized NMR (CP)right), and (c) XPS spectra (C1s-left and O1s-right) of Pre/GO-M1 and SOD/GO-M1 composite membranes. 
The $\mathrm{H}_{2} / \mathrm{CO}_{2}$ separation performance was measured with the $\mathrm{H}_{2} / \mathrm{CO}_{2}$ binary gas mixture (each gas component $100 \mathrm{~mL} \mathrm{~min}^{-1}$ ). As a control experiment, the Nylon substrate show very high $\mathrm{H}_{2}$ permeance (29100 GPU) and basically no selectivity (1.5). The SOD/GO-M1 possess $\mathrm{H}_{2}$ permeance of $~ 1050$ GPU and $\mathrm{H}_{2} / \mathrm{CO}_{2}$ selectivity of 105 at room temperature, which is superior compared with the reported pure zeolite membranes (Tables S5-S7 and Fig. S18). The competition between the two molecules resulted in a slight decrease of the permeance of the SOD/GO-M1 membrane for both gases, i.e. for $\mathrm{H}_{2}$ : from 1200 to $1050 \mathrm{GPU}$, and $\mathrm{CO}_{2}$ from 15 to $10 \mathrm{GPU}$. The hydrogen alone in the channels is finely affected by the competitive diffusion, leading to the higher $\mathrm{H}_{2} / \mathrm{CO}_{2}$ selectivity. For the reforming gas purification in precombustion $\mathrm{CO}_{2}$ capture, the working conditions involve high temperature and steam, the stability of SOD/GO-M1 membrane was evaluated at $200{ }^{\circ} \mathrm{C}$, exposed to an equimolar $\mathrm{H}_{2} / \mathrm{CO}_{2}$ feed containing 4 mol. \% water vapour. The water vapor in the hydrogen-enriched permeate is beneficial for controlling the flame temperature in the combustor and also for increasing the mass flow. If water does not permeate with $\mathrm{H}_{2}$ in the membrane then the $\mathrm{CO}_{2}$-enriched stream has to be dried using molecular sieves or glycol before it can be liquefied. This increases the cost and complexity of the separation process. The membrane exhibits $\mathrm{H}_{2}$ permeance of $\sim 4900 \mathrm{GPU}$ and $\mathrm{H}_{2} / \mathrm{CO}_{2}$ selectivity of 56 . Furthermore, the SOD/GO-M1 can maintain its $\mathrm{H}_{2} / \mathrm{CO}_{2}$ separation performance after several vapour switching on/off cycles during $50 \mathrm{~h}$ (Fig. 3). The presence of $\mathrm{H}_{2} \mathrm{O}$ molecules can hinder the diffusion of gases, resulting in the decreased permeance. The potential densification issue of the membrane with long term exposure to water vapors will be addressed in our future research. ${ }^{24}$ The coupling of GO and SOD alleviates the plugging of SOD. ${ }^{25}$ The close cross-linking of GO and SOD improves gas separation selectivity by means of the screening effect of SOD; a severe decline in the selectivity due to the swelling of the layer spacing by water has been previously observed. ${ }^{26}$ The flexible GO still ensures free diffusion of gases between the layers, and a large number of embedded nanosized SOD crystals improve substantially the gas separation efficiency (Scheme S2). 


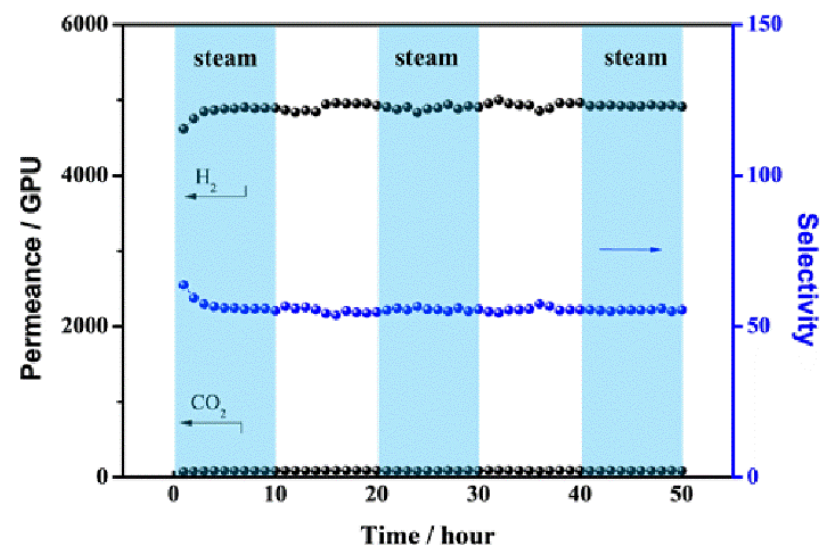

Figure 3. $\mathrm{H}_{2} / \mathrm{CO}_{2}$ permeance and selectivity of SOD/GO-M1 membrane versus vapour switching on/off cycles and test time.

In summary, the SOD/GO composite membranes were prepared by direct transformation of amorphous precursor particles infiltrated in GO matrix. More importantly, the intimate bonding between GO and SOD crystals resulted in thin membranes with high selectivity due to the presence of SOD molecular sieve and high permeability due to the layered GO. The synergistic effect between GO and SOD promote high thermal stability and water resistance of SOD/GO composite membranes, which possesses $\mathrm{H}_{2}$ permeance of $4900 \mathrm{GPU}$ and $\mathrm{H}_{2} / \mathrm{CO}_{2}$ selectivity of 56 at $200{ }^{\circ} \mathrm{C}$ with steam. The advantages of SOD/GO composite membrane achieved are as follows: (i) monodispersed nanosized SOD crystals are formed in the GO matrix promoting the high gas permeance, (ii) the SOD nanocrystals enhanced the selectivity towards $\mathrm{H}_{2}$, and (iii) the interactions between the aluminoslicate precursor particles and the GO prevent the "sieve-in-a-cage" scenario, which is often the problem for MMMs. Work is in progress to extend this approach to other potential zeolite family, the potential densification issues with long term exposure to water vapors (100h, 500h, 1000h) as well as stress-resistance under different pressures (5 - $50 \mathrm{bar})$.

\section{Acknowledgements}

This work was supported from Thousand Talents Program for Foreign Experts (WQ20152100284), National Natural Science Foundation of China (Grants No. 21991091, U1862118, 21501198, 21601205 and 21771193), Taishan Scholar Foundation (ts201511019) and the Fundamental Research Funds for the 
Central Universities (18CX02047A, 18CX07001A, 18CX05018A), PetroChina Innovation Foundation (2019D-5007-0411), Key Research and Development Projects of Shandong Province (2019JZZY010331).

\section{Reference}

[1]N. Rangnekar, N. Mittal, B. Elyassi, J. Caro and M. Tsapatsis, Chem. Soc. Rev. 2015, 44, 7128-7154. [2](a)Y. Tian, L. Fan, Z. Wang, S. Qiu and G. Zhu, J. Mater. Chem. 2009, 19, 7698-7703; (b) Z. Wang, J. Shao and Q. Ge, Petrochemical Technology 2010, 39, 583-591.; (c) M. A. Carreon, S. Li, J. L. Falconer and R. D. Noble, J. Am. Chem. Soc. 2008, 130, 5412-5413.; (d) Y. Li, J. Liu and W. Yang, J. Membr. Sci. 2006, 281, 646-657.; (e) T. C. T. Pham, H. S. Kim and K. B. Yoon, Science 2011, $334,1533-1538$.

[3](a) X. Xu, Y. Bao, C. Song, W. Yang, J. Liu and L. Lin, Microporous Mesoporous Mater. 2004, 75, 173-181.; (b) J. Yu, C. Qi, J. Zhang, C. Bao and H. Xu, J. Mater. Chem. A 2015, 3, 5000-5006.; (c) F. Jiao, H. Guo, Y. Chai, H. Awala, S. Mintova and C. Liu, J. Catal. 2018, 368, 89-97.

[4] T. C. Merkel, M. Zhou, R.W. Baker, J. Membr. Sci. 2012, 389, 441--450.

[5](a) B. Comesaña-Gándara, J. Chen, C. G. Bezzu, M. Carta, I. Rose, M. Ferrari, E. Esposito, A. Fuoco, J. C. Jansen, N. B. McKeown, Energ. Environ. Sci. 2019, 12, 2733-2740. (b) X. Guo, Z. Qiao, D. Liu, C. Zhong, J. Mater. Chem. A. 2019, 7, 24738-24759.; (c) J. Dechnik, C. J. Sumby, C. Janiak, Cryst. Growth. De. 2017, 17, 4467-4488.

[6]Y. S. Lin and M. C. Duke, Curr. Opin. Chem. Eng. 2013, 2, 209-216.

[7]J. Wang, S. Wang, Q. Xin and Y. Li, J. Mater. Chem. A 2017, 5, 6794-6816.

[8](a) D. Li, H. Y. Zhu, K. R. Ratinac, S. P. Ringer and H. Wang, Micropor. Mesopor. Mat. 2009, 126, 14-19.; (b) G. Yang, H. Guo, Z. Kang, L. Zhao, S. Feng, F. Jiao and S. Mintova, ChemSusChem 2018, 12,4529 . 
[9](a) S. Shu, S. Husain and W. J. Koros, J. Phys. Chem. C 2007, 111, 652-657.; (b) N. Kosinov, J. Gascon, F. Kapteijn and E. J. M. Hensen, J. Membr. Sci. 2016, 499, 65-79.

[10] (a) L. Chen, G. Shi, J. Shen, B. Peng, B. Zhang, Y. Wang, F. Bian, J. Wang, D. Li, Z. Qian, G. Xu, G. Liu, J. Zeng, L. Zhang, Y. Yang, G. Zhou, M. Wu, W. Jin, J. Li and H. Fang, Nature 2017, 550, 380-383.; (b) S. Wang, Y. Xie, G. He, Q. Xin, J. Zhang, L. Yang, Y. Li, H. Wu, Y. Zhang, M. D. Guiver and Z. Jiang, Angew. Chem. Int. Ed. 2017, 56, 14246 -14251.; (c) C. Chi, X. Wang, Y. Peng, Y. Qian, Z. Hu, J. Dong and D. Zhao, Chem. Mater. 2016, 28, 2921-2927.

[11] (a) B. Mi, Science 2014, 343, 740-742.; (b) Z. Jia and W. Shi, Carbon 2016, 101, 290-295.; (c) K. Guan, D. Zhao, M. Zhang, J. Shen, G. Zhou, G. Liu and W. Jin, J. Membr. Sci. 2017, 542, 41-51.

[12]M. Jia, Y. Feng, S. Liu, J. Qiu and J. Yao, J. Membr. Sci. 2017, 539, 172-177.

[13] T.S. Chung, L. Y. Jiang, Y. Li and S. Kulprathipanja, Prog. Polym. Sci. 2007, 32, 483-507.

[14]E. M. Flanigen, H. Khatami and H. A. Szymansk, Adv. Chem. Ser. 1971, 101, 201-227.

[15]B. Z. Zhan, M. A. White, M. Lumsden, J. Mueller-Neuhaus, K. N. Robertson, T. S. Cameron and M. Gharghouri, Chem. Mater. 2002, 14, 3636-3642.

[16]Lippmaa, M. Magi, A. Samoson, M. Tarmak and G. Engelhardt, J. Am. Chem. Soc. 1981, 103, 49924996.

[17]T. Oh and C. K. Choi, J. Korean. Phys. Soc. 2010, 56, 1150-1155.

[18] K. Albert and E. Bayer, J. Chromatogy. A. 1991, 544, 345-370

[19] (a) S. Fasolin, M. Romano, S. Boldrini, A. Ferrario, M. Fabrizio, L. Armelao and S. Barison, J. Mater. Sci. 2018, 54, 2049-2058.; (b) M. Sen, K. Dana and N. Das, Ultrason. Sonochem. 2018, 48, 299-310.; (c) T. F. Mastropietro, A. Brunetti, P. F. Zito, T. Poerio, H. Richter, M. Weyd, S. Wöhner, E. Drioli and G. Barbieri, Sep. Purif. Technol. 2015, 156, 321-327.

[20](a) H. Li, Z. Song, X. Zhang, Y. Huang, S. Li, Y. Mao, H. J. Ploehn, Y. Bao, M. Yu, Science 2013,342, 95-98.; (b) H. W. Kim, H. W. Yoon, S.-M. Yoon, B. M. Yoo, B. K. Ahn, Y. H. Cho, H. J. Shin, H. Yang, U. Paik, S. Kwon, J.-Y. Choi, H. B. Park, Science 2013, 342, 91-95. 
[21] (a) K. A. Stevensa, J. D. Moona, H. Borjiginc, R. Liuc, R. M. Josephc, J. S. Rifflec, B. D. Freeman, J. Membr. Sci. 2020, 593, 117427;(b) J. C. Jansen, E. Esposito, A. Fuoco, M. Carta, Polymers 2019, 11, 844. (c) A. Fuoco, B. Satilmis, T. Uyar, M. Monteleone, E. Esposito, C. Muzzi, E. Tocci, M. Longo, M. P. De Santo, M. Lanč, K. Friess, O. Vopička, P. Izák, J. C. Jansen, J. Membr. Sci. 2020, $594,117460$.

[22] (a) T. V. Gestel, J. Barthel, J. Membr. Sci. 2018, 554, 378-384.; (b) R.S.A. de Lange, J.H.A. Hekkink, K. Keizer, A.J. Burggraaf, Microporous Mater. 1995, 4, 169-186.

[23] J. Yu, H. Lim, S. Lee, J. Phys. Chem. C. 2019, 123, 25761-25768.

[24] (a) V. Boffa, D. Blank, J. Tenelshof, J. Membr. Sci. 2008, 319, 256; (b) J. Yu, H. Lim, S. Lee, J. Phys. Chem. C. 2019, 123, 25761.

[25] J. C. Poshusta, R. D. Noble and J. L. Falconer, J. Membr. Sci. 2001, 186, 25-40.

[26]S. Zheng, Q. Tu, J. J. Urban, S. Li and B. Mi, ACS Nano. 2017, 11, 6440-6450. 


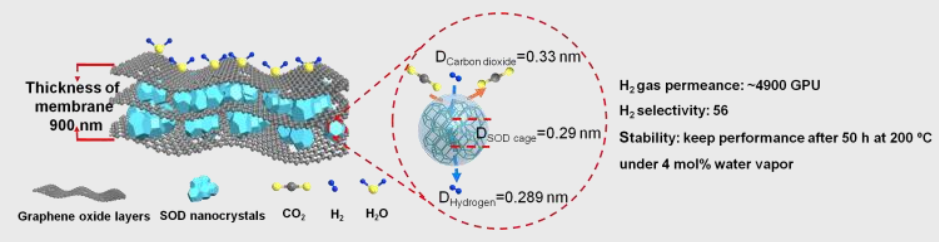

The cross-linking between sodalite (SOD) nanoparticles with an aperture size of $2.9 \AA$ with flexible 2D layers of graphene oxide (GO) in the membranes promoted both the high gas permeance and enhanced selectivity towards hydrogen from a mixture containing $\mathrm{CO}_{2}$ and water.
Hailing Guo"l, Guodong Kong",

Ge Yangll, Jia Pang, Zixi Kang*,

Shou Feng, Lei Zhao, Lili Fan,

Liangkui Zhu, Aurélie Vicente,

Peng Peng, Zifeng Yan,

Daofeng Sun*, Svetlana 